\title{
THERMODYNAMIC SIMULATION OF YEAR ROUND AIR CONDITIONING SYSTEM FOR VARIABLE ROTATIONAL SPEED OF DESICCANT WHEEL
}

\author{
Shankar Kumar ${ }^{1}$, S.P.S. Rajput ${ }^{2}$, Arvind Kumar ${ }^{3}$ \\ ${ }^{1,}$ Research scholar, Department of Mechanical Engineering, Maulana Azad National Institute of Technology, Bhopal, \\ 462051 - India. \\ ${ }^{2}$ Professors, Department of Mechanical Engineering, Maulana Azad National Institute of Technology, Bhopal, \\ 462051 - India. \\ ${ }^{3}$ Assistant Professor, Department of Mechanical Engineering, Maulana Azad National Institute of Technology, \\ Bhopal, 462051 - India.
}

\begin{abstract}
This paper presents a study on different kinds of air conditioning systems in association to existing one to use through of the year. The system have generally desiccant wheel, evaporative cooler, heating coils and cooling coil. Mainly the system imparts all three regular weather conditions. Like hot and dry, hot and wet and cool and dry. For this the out let condition will be fixed $25^{\circ} \mathrm{C} d r y$ bulb temperature (DBT) and 50\% relative humidity. In the present paper, for maintaining room condition thermodynamic simulation is being done. If rotational speed of desiccant wheel is changed, the year round air conditioning equipments change own parameter to maintain the room condition. The paper also shows the variation in supply condition of air, volume of cellulose cooling pad of evaporating cooler, temperature of cooling coil in hot and wet weather conditions with respect to rotational speed of desiccant wheel (6 to 24rph).The outlet temperature of desiccant wheel increases 52.96 to $63.28^{\circ} \mathrm{C}$.The efficiency of desiccant wheel increases where as saturation efficiency of evaporative cooler decreases. The volume of cooling pad decreases from 547.99 to $439.54 \mathrm{~cm}^{3}$ w.r.t. the rotational speed of desiccant wheel. The DBT and the specific humidity of supply air remain constant with the change of rotational speed of desiccant wheel.
\end{abstract}

Key Words: Heating coil, Cooling coil, Desiccant Wheel, Cellulose cooling pad, Supply condition.

\section{INTRODUCTION}

Air conditioning system plays an important role in industry, infrastructure and domestic use. For different weather condition different air conditioning systems are used. There is no such single air conditioning system which gives constant output (comfort) throughout the whole year .The existing air conditioning system works better only in the specified weather condition. While human body requires comfort throughout the year. The human body can be considered as thermal machine with $20 \%$ thermal efficiency. The remaining $80 \%$ must be disposed off from body to the surrounding which depends upon temperature and humidity of surrounding otherwise the accumulation of heat result and causes discomforts in the form of body pain, heat cramp or shocks, heat stroke, heat exhaustion.

There are following psychometric process for air conditioning. (a) Heating and humidification (b) Cooling and dehumidification (c) Cooling and humidification

Heating and humidification: In this process for humidification, evaporative cooler is used and heating purpose heating coil is used.

Cooling and humidification: This process is used generally in summer air conditioning to cool and humidify the air. In which air is first partial cool and humidify by evaporating cooling and after that is cool by sensible cooling from cooling coil.

Cooling and dehumidification: This process is used in summer (rainy) season air conditioning to cool and dehumidify the air. The humidification is done by two methods. (1)By desiccant wheel and (2) By cool the cooling coil up to dew point temperature.

The above problem of human body due to exiting air conditioning system and psychometric process, year round air conditioning system is required. It have following components.(1) Fan(2)Desiccant wheel (3)Cooling pad(4)Cooling coil(5)Heating coil.

Shankar Kumar et al [1] worked on the actual position of equipment used in year round air conditioning system. They also studied about the parameters on which the system depends.

F.Moukalled et al [2] reported, about the use of CFD for predicting and improving the performance of air conditioning equipment .They reported a full numerical model for the concurrent forecast of velocity, temperature and humidity of air flowing in an air conditioning unit.Zainab Hasson et al [3] presented an efficient methodology to design modified evaporative air -cooler for 
winter air-conditioning in Baghdad city. The performance is reported in terms of effectiveness of DEC, saturation efficiency of DEC, outlet temperature of air and cooling capacity.D.La.et al[4]study, rotary desiccant air conditioning system, which combines the technology of desiccant dehumidification and evaporative cooling. It evaluates the status of rotary desiccant dehumidification and air conditioning system in the following two aspects ;( 1) Improvement of advanced desiccant materials and (2) Optimization of system arrangement. E.velasco et al [5] study about actual evaporating cooling method .They explain that when in an isolated system water and air supposed to be in contact, if air gains enthalpy then water loose it, being cooled, while if air looses enthalpy, water would be heated .Thus in a process where air and water are in contact, water will always tend to adiabatic saturation temperature. Kulkarni and Rajput [6] studied about the theoretical performance analysis of cooling pads of different materials for evaporative cooler. The material have been considered, rigid cellulose, corrugated paper, corrugated high density polythene and aspen fiber .It has been observed that the saturation efficiency decreases with increasing mass flow rate of air .It also seen that material with higher wetted surface area gives higher saturation efficiency.Fatemeh et al[7]shown the modeling of a desiccant wheel used for dehumidifying the ventilation air of an air-conditioning system. By the numerical method, the performance of an adiabatic rotary dehumidification is parametrically studied and the optimums rotational speed is determined by examine the outlet adsorption -side humidity profiles.

D.G. Waugaman et al [8] studied about the advantages and disadvantages of desiccant wheel. It states that the main advantage of desiccant cooing is significant potential for energy reduction and reduced utilization of fossil fuels. The electrical energy necessity can be very low comparing with conventional refrigeration system.Kang and Maclain-cross [9] showed that dehumidification is the key factor of desiccant cooling system and the cooling COP can be significant enhanced by enhancing the performance of component.J.J. Jurinak et al and F.E.Nia et [10] premeditated about the desiccant process that in this process, fresh air is dehumidified and then sensibly and evaporatively cooled before being sent to the conditioned space. This method works without conventional refrigerants, and also it allows the use of low-temperature heat to drive cooling cycle. It also shows that, the moisture can be removed from the desiccant by heating it to temperature around $60^{\circ} \mathrm{C}-90^{\circ} \mathrm{C}$ and revealing it to a regenerative air stream.

Camrago, J. R., et al [11] studied about the fundamental ideology of the evaporative cooling process for human thermal comfort, the ideology of operation for the direct evaporative cooling system and the mathematical development of the equations of thermal exchanges, allowing the purpose of the effectiveness of saturation. Dowdy, J.A., Karbash,N.S.[12]obtained the heat and mass transfer coefficient by experimentally for the evaporative cooling process through various thicknesses of rigid impregnated cellulose evaporative medium. E.V.Gomez et al [13] studied about the comparison of high grade energy required in air-conditioning system and evaporating cooling system. The weather data for analysis has taken from IMD Bhopal[19] for the year 2013.Neti, S., Wolfe,E.I.[14] calculated the effectiveness in a silica gel rotary exchanger for 0.5 to $2.5 \mathrm{~m} / \mathrm{s}$ process air flow velocity and 20 to $30^{\circ} \mathrm{C}$ temperature ranged with 30 to $100 \%$ relative humidity.

\section{Nomenclature}

$\mathrm{h}$

$\mathrm{T}_{\mathrm{w}}$

$\mathrm{W}$

$\mathrm{R}$

mass

RTH

RTHO

RSHF

Dry bulb temperature of air

\section{$\mathrm{RSH}$}

RSHO

CLC

$\mathrm{C}_{\mathrm{pa}}$

$\mathrm{C}_{\mathrm{pv}}$

$(\mathrm{j} / \mathrm{kg}-\mathrm{k})$

$\mathrm{V} \quad$ Volume of cooling pad

B Bi-pass factor

$\mathrm{T}_{\mathrm{c}} \quad$ Cooling coil temperature

$\mathrm{T}_{\mathrm{rh}} \quad$ Temperature of re-heat coil

$\mathrm{T}_{\mathrm{ph}} \quad$ Temperature of pre-heat coil

$\mathrm{T}_{\mathrm{rd}} \quad$ Regeneration temperature of desiccant wheel

$\mathrm{P} \quad \%$ mixing of re-circulated air to atmospheric air

$\mathrm{M}_{\mathrm{m}} \quad$ Mass flow rate of air in duct after mixing $(\mathrm{kg} / \mathrm{s})$

of ambient air and re-circulating air

RDW Radius of desiccant wheel

dt Thickness of desiccant coating $(\mathrm{mm})$

Dh Hydraulic diameter of a channel (mm)

N Desiccant wheel speed

Greek letters

$\varphi \quad$ Relative humidity of air(\%)

$\rho \quad$ Density of $\operatorname{air}\left(\mathrm{kg} / \mathrm{m}^{3}\right)$

$\eta \quad$ Saturation efficiency of evaporative cooler $(\%)$

$\varepsilon \quad$ Efficiency of desiccant wheel.

\section{Subscripts}

$\mathrm{Ph} \quad$ pre-heating coil

rh re-heating coil

c cooling coil

phi pre- heating coil inlet

pho pre -heating coil outlet

di desiccant wheel inlet

do desiccant wheel outlet

ei evaporative cooler inlet

eo evaporative cooler outlet

ci cooling coil inlet

co cooling coil outlet

rhi re-heat coil inlet

rho re-heat coil outlet

a ambient

s supply

r room

$\mathrm{m} \quad$ mixed air 


\section{METHODOLOGY}

Following assumptions and equations have been taken for analysis.

\subsection{Assumption}

[1]. The wet bulb temperature before and after the evaporative cooler will be constant.

[2]. The cooling coil and heating coil be only used for sensible cooling and sensible heating.

[3]. The mass flow rate (or air velocity) will be same throughout the duct.

[4]. Axial heat conduction and water vapour diffusion in the air is negligible.

[5]. Axial molecular diffusion within the desiccant is negligible.

[6]. The channels are assumed adiabatic and impermeable.

[7]. The heat and mass transfer coefficient are constant.

[8]. The adsorption heat per kilogram of adsorbed water in desiccant wheel is constant.

\subsection{Equations}

2.2.1 Equation of specific humidity for mixed air.

$$
W_{m}=\frac{R \times W_{a}+W_{r}}{1+W_{a}}
$$

2.2.2 Equation of enthalpy for mixed air [15].

$$
h_{m}=\frac{R \times h_{a}+h_{r}}{1+R}
$$

2.2.3 Equation of DBT for mixed air[15].

$$
T_{m}=\frac{\left(h_{m}-2.5 \times W_{m}\right)}{\left(1.01+0.000189 \times W_{m}\right)}
$$

2.2.4 Equation of enthalpy for supply air [15].

$$
h_{s}=\frac{\left(M_{m} \times h_{r}-R T H\right)}{M_{m}}=\frac{\left(M_{m} \times h_{r}-3.5168525 \times C L C\right]}{M_{m}}
$$

2.2.5 Equation of DBT for supply air [15].

$$
T_{s}=T_{r}-\frac{R S H}{\left(1.148314607 \times M_{m}\right)}
$$

2.2.6 Equation for saturation efficiency of evaporative cooler $[5,16]$.

$$
\eta=\frac{\left(T_{E i}-T_{E 0}\right)}{\left(T_{e i}-T_{\text {wei }}\right)}
$$

Where

$$
T_{\text {ei }}=T_{\text {do }} \text { and } T_{\text {wdo }}=T_{\text {wei }}=T_{\text {weo }}
$$

2.2.7 Equation for volume of cooling pad.[5]

$$
V_{s}=\frac{\left(c_{p a}+W_{e i} \times c_{p v}\right) \times M_{m} \times \ln [1-\eta]}{\left(-h_{D} \times 370\right)}
$$

Where

$$
W_{d o}=W_{\text {ei }}
$$

2.2.8 Equation for percentage mixing of re-circulated air with atmospheric air.

$$
P=\frac{100}{\left(1+m_{1} / m_{n}\right)}=\frac{100}{(1+R)}
$$

2.2.9 Equation for temperature of cooling coil.

$$
T_{c}=\frac{\left(T_{g}-B \times T_{e 0}\right)}{(1-B)}
$$

2.2.10 Area of desiccant wheel in which mixed air is passed

$$
A=\frac{\pi \times(R D W)^{2}}{2}
$$

2.2.11 Equation for velocity of air

$U=\frac{M_{m}}{\left(\rho_{a} \times A\right)}$

2.2.12 Equation for efficiency of desiccant wheel [16].

$\varepsilon=\mathrm{k}_{1}(\mathrm{~N}) \mathrm{k}_{2}\left(T_{m}\right) \mathrm{k}_{3}(\mathrm{dt}) \mathrm{k}_{4}\left(T_{r d}\right) \mathrm{k}_{5}\left(W_{m}\right) \mathrm{k}_{6}\left(D_{h}\right) \mathrm{k}_{7}(\mathrm{U})$

Where

$\mathrm{k}_{1}(\mathrm{~N})=-0.0001 \mathrm{~N}^{2}+0.0042 \mathrm{~N}+0.4474$

$\mathrm{k}_{2}\left(T_{m}\right)=-0.0001\left(T_{m}\right)^{2}-0.0031 T_{m}+0.8353$

$\mathrm{k}_{3}(\mathrm{dt})=-21.67(\mathrm{dt})^{2}+6.93 \mathrm{dt}+1.34$

$\mathrm{k}_{4}\left(T_{r d}\right)=-0.0001\left(T_{r d}\right)^{2}+0.0355\left(\mathrm{~T}_{\mathrm{rd}}\right)-0.4924$

$\mathrm{k}_{5}\left(W_{m}\right)=592.77\left(W_{m} / 1000\right)^{2}-41.23\left(W_{m} / 1000\right)+1.283$

$\mathrm{k}_{6}\left(D_{h}\right)=-0.0572\left(D_{h}\right)^{3}+0.0933\left(D_{h}\right)^{2}+0.6139 D_{h}-0.0922$

$\mathrm{k}_{7}(\mathrm{U})=-0.0611 \mathrm{U}+0.8376$

2.2.13 Equation for outlet DBT of desiccant wheel [17].

$T_{\text {do }}=$

$p_{1}(N) p_{2}\left(T_{m}\right) p_{3}(d t) p_{4}\left(T_{r d}\right) p_{5}\left(W_{m}\right) p_{6}\left(D_{h}\right) p_{7}(U)$

Where

$$
P_{1}(N)=-0.0002 N^{2}+0.0112 N+0.420
$$

$$
\begin{gathered}
p_{2}\left(T_{m}\right)=-0.0001\left(T_{m}\right)^{2}+0.0275 T_{m}+0.7993 \\
p_{3}(d t)=-18.79(d t)^{2}+7.92 d t+1.75 \\
p_{4}\left(T_{r d}\right)=-0.0004\left(T_{r d}\right)^{2}+0.1255 T_{r d}+0.6757
\end{gathered}
$$

$\mathrm{p}_{5}\left(\mathrm{~W}_{\mathrm{m}}\right)=594.48\left(\mathrm{~W}_{\mathrm{m}} / 1000\right)^{2}+26.76\left(\mathrm{~W}_{\mathrm{m}} / 1000\right)+3.79$

$\mathrm{p}_{6}\left(D_{h}\right)=0.039\left(D_{h}\right)^{3}+0.026\left(D_{h}\right)^{2}+0.603 D_{h}+0.0912$

$$
\mathrm{p}_{7}(\mathrm{U})=-0.060 \mathrm{U}+0.7973
$$

2.2.14 Equation for specific humidity of outlet air for desiccant wheel $[17,18]$

$$
W_{d o}=\left(W_{m}-\varepsilon W_{m}\right)
$$

\section{SYSTEM DESCRIPTION}

The positions of equipments used in year round air conditioning system are shown in the diagram of year round air conditioning system(Fig.1).The analysis is done on the concept that, supply air condition is depends on the room conditions, mass flow rate, CLC, and RSHF. We take the room conditions be constant. So the supply condition will be depends on mass flow rate, CLC and RSHF. 


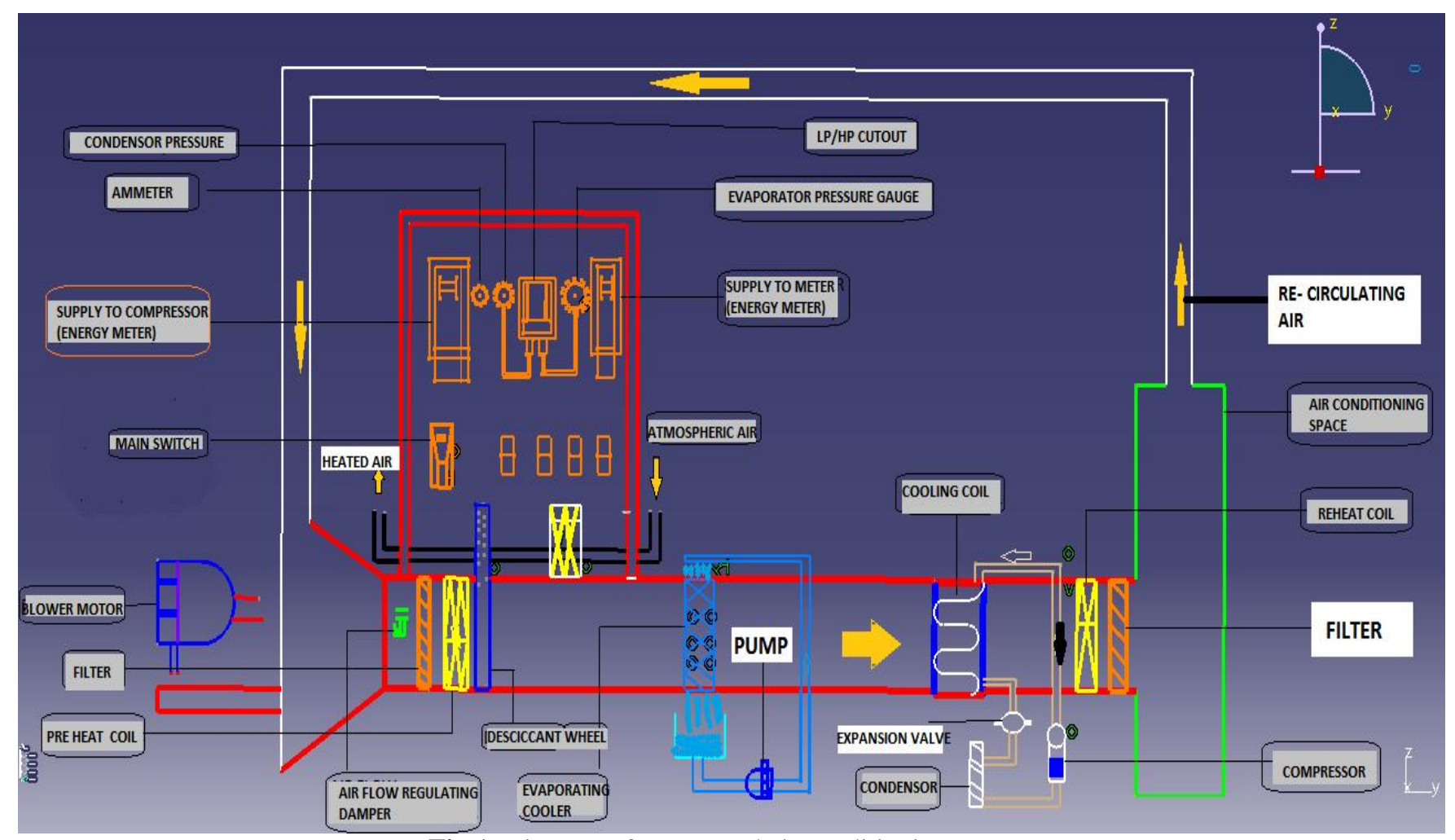

Fig.1. Diagram of year round air conditioning system

For hot and dry weather condition the supply air condition is also the outlet condition of cooling coil. Because from cooling coil only sensible cooling is done, so the inlet and outlet specific humidity of air for cooling coil will be same. The inlet condition of cooling coil is same the outlet condition of the evaporative cooler, and the WBT of inlet and outlet air of evaporating cooler will be same, which is equal to the WBT of mixed air .So the outlet condition of evaporative cooler is find with the online psychometric calculator [20]. Hence we find out the saturation efficiency of evaporative cooler and the volume of cellulose cooling pad with the help of inlet and outlet condition of evaporating cooler. For hot and wet weather condition, inlet condition of evaporative cooler and outlet condition of desiccant wheel is same and it depends on atmospheric condition of air, mixing ratio of air, rotational speed and regeneration temperature of desiccant wheel. The same concept of hot and dry weather condition is used for evaporative cooler and cooling coil. In cold and dry weather condition, the mixed air is passed through pre-heating coil in which air is heated at constant specific humidity , after that air is passed through evaporative cooler in which air is humidified at constant wet bulb temperature and lastly air is heated up to required supply condition by re-heating coil.

\section{RESULT AND DISCUSSION}

\begin{tabular}{|l|l|l|l|l|l|l|l|}
\hline $\mathrm{RPH}$ & 6 & 9 & 12 & 15 & 18 & 21 & 24 \\
\hline $\mathrm{Tm}\left({ }^{\circ} \mathrm{C}\right)$ & 27.57 & 27.57 & 27.57 & 27.57 & 27.57 & 27.57 & 27.57 \\
\hline $\mathrm{Tdo}\left({ }^{\circ} \mathrm{C}\right)$ & 52.96 & 55.67 & 57.99 & 59.91 & 61.43 & 62.55 & 63.28 \\
\hline $\mathrm{Teo}\left({ }^{\circ} \mathrm{C}\right)$ & 42.92 & 45.23 & 47.11 & 48.81 & 50.14 & 51.17 & 51.97 \\
\hline $\mathrm{Tc}\left({ }^{\circ} \mathrm{C}\right)$ & 17.76364 & 17.18624 & 16.71614 & 16.29114 & 15.95864 & 15.70114 & 15.50114 \\
\hline $\mathrm{Ts}\left({ }^{\circ} \mathrm{C}\right)$ & 22.79491 & 22.79491 & 22.79491 & 22.79491 & 22.79491 & 22.79491 & 22.79491 \\
\hline $\mathrm{Wm}(\mathrm{g} / \mathrm{kg})$ & 17.384 & 17.384 & 17.384 & 17.384 & 17.384 & 17.384 & 17.384 \\
\hline $\mathrm{Wdo}(\mathrm{g} / \mathrm{kg})$ & 6.260594 & 6.068484 & 5.919065 & 5.812337 & 5.748301 & 5.726955 & 5.748301 \\
\hline $\mathrm{Weo}(\mathrm{g} / \mathrm{kg})$ & 10.33 & 10.33 & 10.33 & 10.33 & 10.33 & 10.33 & 10.33 \\
\hline $\mathrm{Ws}(\mathrm{g} / \mathrm{kg})$ & 10.33 & 10.33 & 10.33 & 10.33 & 10.33 & 10.33 & 10.33 \\
\hline$\varepsilon$ & 0.639865 & 0.650916 & 0.659511 & 0.66565 & 0.669334 & 0.670562 & 0.669334 \\
\hline$\eta(\%)$ & 33.30311 & 32.36258 & 31.90937 & 31.18182 & 30.69405 & 30.24165 & 29.62732 \\
\hline $\mathrm{V}\left(\mathrm{cm}^{3}\right)$ & 547.9984 & 514.0822 & 493.8579 & 472.2523 & 458.6481 & 448.977 & 439.5406 \\
\hline
\end{tabular}

4.1: Hot and wet weather condition. Variation of parameters w.r.t. RPH of desiccant wheel. 

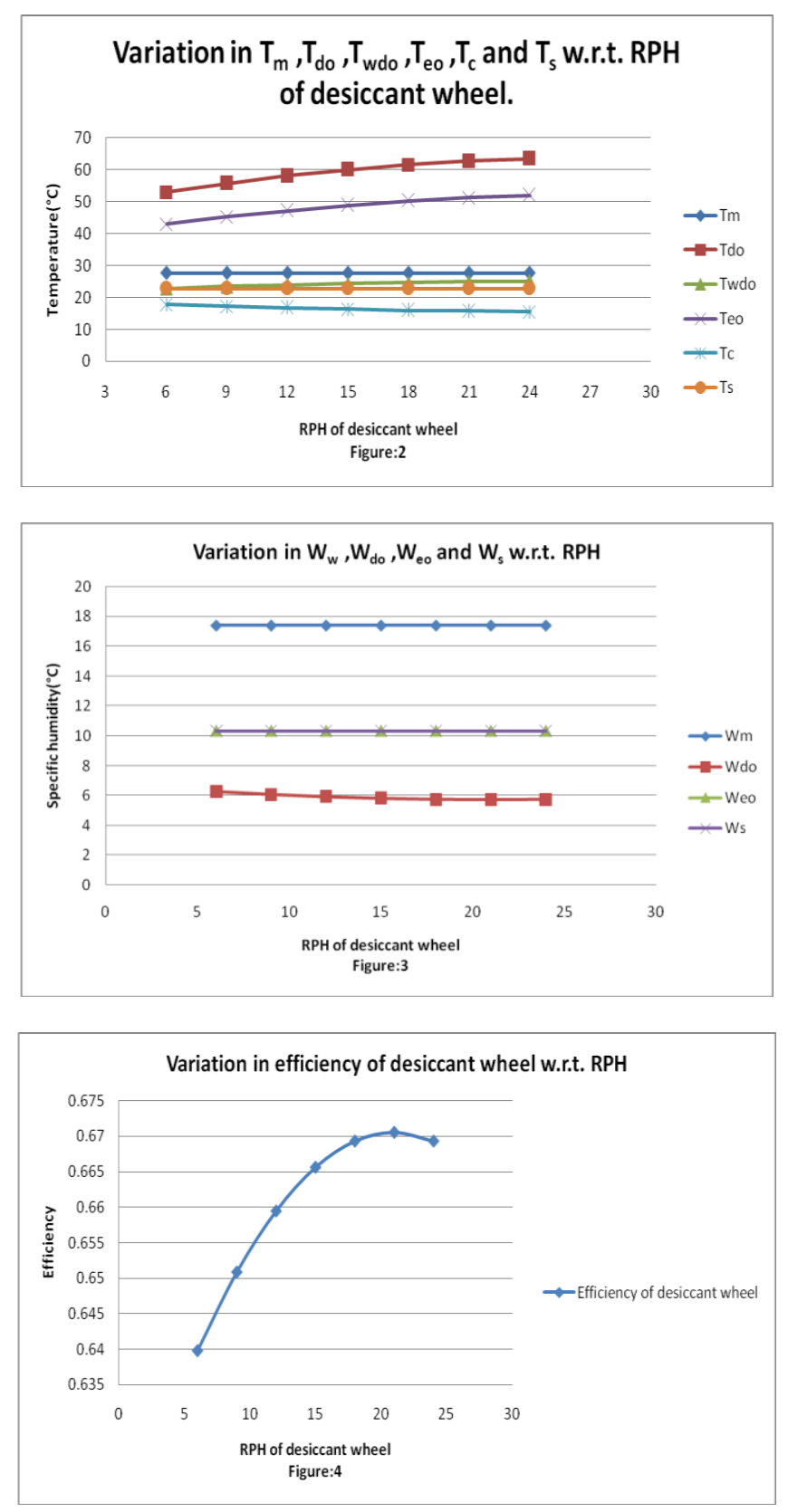

Figure (2) indicates variation in temperature w.r.t rotational speed of desiccant wheel respectively. The inlet temperature of desiccant wheel or mixed air temperature remains constant because it depends on atmospheric condition and the re-circulated air condition and both are constant. The value of $\mathrm{T}_{\mathrm{do}}$ also increases with increase in rotational speed of desiccant wheel. The result shows that the supply condition be constant because the supply condition is depends on the mass flow rate ,Room conditions, RTH or cooling load and RSHF value and these parameters are taken to be constant. The cooling coil temperature decreases, since the supply air DBT is constant and the inlet of cooling coil that is outlet of evaporative cooler DBT of air increases and the bypass factor be constant. From table (1), the value of specific humidity of outlet air of evaporative cooler is constant, because the specific humidity of supply air is constant and it is equal to specific humidity of outlet air of evaporative cooler. The value of effectiveness of desiccant wheel firstly increases and a certain value of rotational speed of it decreases. Because at constant mass flow rate and regeneration temperature, the rotational speed of a rotary desiccant dehumidification is inversely proportional to the sorption time. The rotational speed of a rotary desiccant dehumidifier is optimum when the average outlet humidity ratio of the process air flow is the minimum. A rotary desiccant dehumidifier operates such that the moisture observed during the adsorption process, so when the average outlet humidity ratio in the adsorption stream is optimized, the average outlet humidity ratio of the regeneration stream is maximized. In other words, the adsorption and regeneration process will be optimum at the same rotational speed. When a desiccant wheel rotates much faster than optimum speed, the adsorption and regeneration process are too short, which result in poor performance. Also, when the rotational speed is low the adsorption and regeneration process are too long and less effective.The volume of cooling pad of evaporative cooler decreases with increase in rotational speed of desiccant wheel. The outlet air specific humidity of desiccant wheel or inlet air specific humidity of evaporative cooler firstly decreases and after a optimum speed it increases because the effectiveness is maximum at optimum rotational speed. The outlet specific humidity of evaporating cooler is constant and which is only possible when volume of the cooling pad decreases. Because as volume or thickness is decreases then the air has lesser contact time with water for same mass flow rate.The saturation efficiency of evaporative cooler decreases as volume of cooling pad decreases.

\section{CONCLUSION}

After going through thermodynamic analysis of year round air conditioning system for different value of rotational speed of desiccant wheel, the following conclusions were made:

* The analysis of year round air conditioning system depends mainly on the performance of the desiccant wheel, evaporative cooler, heating coil and cooling coil.

* DBT of supply air remain constant with the increase of rotation speed of desiccant wheel for hot and wet weather condition. The DBT of supply air is 22.79491 .

* The specific humidity of supply air also remain constant with the increase of desiccant wheel and which is equal to 10.33 to $\mathrm{g} / \mathrm{kg}$ for hot and wet weather condition.

* The volume of cellulose cooling pad decreases from 547.9984 to $439.5406 \mathrm{~cm}^{3}$ for hot and wet weather condition with increase in RPH (6 to 24) of desiccant wheel.

* The saturation efficiency of evaporative cooler decreases from 33.30311to 29.62732\% for hot and wet weather condition with increase in RPH (6 to 24) of desiccant wheel.

* The efficiency of desiccant wheel increases from 0.639865 to 0.670562 for RPH value 6 to 21 of desiccant wheel and after that it decreases i.e. maximum efficiency exits at the seed $21 \mathrm{RPH}$.

* The cooling coil temperature decreases from 17.76364 to 15.50114 with increase in rotational speed of desiccant wheel( 6 to $24 \mathrm{RPH})$. 


\section{REFERENCES}

[1]. Shankar Kumar, S.P.S. Rajput, and Arvind Kumar, (2014). Thermodynamic Performance Analysis of Year Round Air Conditioning System. International Conference on Industrial, Mechanical and Production Engineering: Advancements and Current Trends(IC IMPACT-2014), November 27-29, Organized by MANIT Bhopal and Co- Sponsored by TEQIP-11

[2]. Moukalled, F., Verma,S.,Darwish ,M.,The use of CFD for Predicting and optimizing the performance of air conditioning equipment. International journal of heat and mass transfer,2011, vol (54), pp (549563).

[3]. Hasson, Z.H., Hanash, Z.H., Experimental Investigation of Evaporative air cooler for winter air conditioning in Baghdad. Al-khwarizmi Engineering journal, 2012, vol (8), pp (62-73).

[4]. La,D.,Dai.,Y.J.,Li.,Wang,R.L., Technical development of rotary desiccant dehumidification and air conditioning. A review, Renewable and sustainable energy reviews, vol(14),pp(130-147), (2010).

[5]. E. Velasco Gomez, F.C. Rey Martinez, A. Tejero Gonzalez, The Phenomenon of evaporative cooling from a humid surface as an alternative method for air-conditioning. International Journal of Energy and Environment,2010, vol (1), pp (69-96).

[6]. Kulkarni, R.K., Rajput, S.P.S., Comparative performance of evaporating cooling pads of alternative materials. International journal of advanced engineering science and technology,2008, vol(10),pp(239-244).

[7]. Fatemech Esfandiari Nia, Dolf Van Paassen, Mohamad Hassan Saidi, Modeling and Simulation of desiccant wheel for air conditioning. Energy and Buildings,2006,vol(38), issue- 10,pp(1230-1239).

[8]. Waugaman, D.G., et al, A Review of Desiccant Cooling System. Energy Recourses Technology Journal,1993, vol (15), pp (1-8).

[9]. Kang, T.S., Maclain-cross, I.L., High performance solid desiccant cooling cycles. Transaction of ASME,1989, vol(111),pp(176-183).

[10]. Jurinak,J.j.,Mitchell,J.W.,Beckman,W.A.,Open-cycle desiccant air conditioning as an alternative to vapour compression cooling in residential application. Transactions of the ASME,1984, vol(106),pp(252258).

[11]. Camrago, J. R., Ebinuma,C.D.,Siveria,J.L., Experimental performance of a direct evaporating cooler operating during summer in Brazilian city. International Journal of Refrigeration,2005,vol(28),pp(1124-1132).

[12]. Dowdy, J.A., Karbash,N.S., Experimental determination of heat and mass transfer coefficient, in rigid impregnated cellulose evaporative media. ASHRAE transaction, 1987,vol (93), pp(382-395).

[13]. Gomez,E.V.,Martinez,F.C.R.,Gonzalez,A.T.,The phenomena of evaporating cooling from a humid surface as an alternative method for air conditioning. International Journal of Energy and Environment, 2010,vol (1), pp (549-563).
[14]. Neti, S., Wolfe,E.I.,Measurement of effectiveness in a silica gel rotary exchanger. Thermal engineering,2000, vol(20),pp(309-322).

[15]. Manohar Prasad,Refrigeration and Air conditioning, $2^{\text {nd }}$ ed ., New Age International(p) Limited,Publishers,New Delhi,2003.

[16]. Beshkani, A., Hosseni, R., Numerical modeling of rigid media evaporative cooler. Applied Thermal Engineering,2007, vol(26),pp(636-643).

[17]. Nia,F.E.,Paasen ,Dolfvan.,Saidi,M.H., Modeling and simulation of desiccant wheel for air conditioning .Energy and building ,2006,vol(38),pp(130-147).

[18]. Zhang, L.Z., Niu, J.L., Performance comparison of desiccant wheel for air dehumidification and enthalpy recovery. Applied Thermal Engineering,2002, vol (22), pp (1347-1367).

[19]. Bhopal weather data from IMD Bhopal.

[20]. Psychometric properties calculator retrieved from http://www.sugartech.co.za 